\title{
PSEUDOMYTHOLOGICAL CONSTELLATION MAPS
}

\section{Andres Kuperjanov}

\begin{abstract}
The objective of the article is to observe how the description of the starry sky has developed by looking at the sky map as a mental composition, a symbolic system that enables orientation in the sky on the basis of a specific integral narrative. The article observes the different ways in which such narratives have emerged and the astromythological essence of these stories. The author attempts to evaluate the nature and development of the different layers of constellations in folk astronomy.
\end{abstract}

Keywords: folk astronomy, stars, constellations, sky maps

In modern times, people are used to seeing patterns in the sky that are clearly outlined and consist of single stars, and people are used to linking these images to mythological content, because the names used for them today often originate in mythology. Even more so, people often develop various interpretations, often beyond the limits of common sense, which can no longer be associated with actual objects in the sky and myths associated with them. But do astral myths that would be associated with specific swarms of stars even exist? How important is the link between mythology and stars? How complex is the system and what stories should we look for in the sky at all? This is the tangle of questions I will try to unravel in the following. The focus will be on the stars and the different motifs that describe and map them.

The questions discussed here were starkly raised during the compilation of the book Eesti taevas (Estonian Sky) (Kuperjanov 2003) and the article is based on a selection of folk astronomy materials collected and published during the last couple of centuries, some source critical analyses and original sources or their copies. I have restricted myself mainly to the European cultural space. I have attempted to avoid contemporary generalising publications that often contain impermissibly essayistic interpretations and instances of free-flowing fantasy. I have tried to find material that is as authentic as possible and on the basis of these materials, I have presented a source critical overview and have also observed intention- 
ally created parallel images, the motifs of their creation and the development of these creations. I assume that originally there must have been a direct connection between the earthly environment and the objects in the sky, almost a one-to-one conformity between an earthly object and its counterpart in the sky. For example, if a star is a hunter, then it is a hunter and there is no essential difference between the hunter in the sky and the hunter in the forest. Both of them carry a bow, both shoot arrows and catch prey. But the development of the mind and science has been distancing from the direct conformity on the level of reflection, which is replaced by increasingly more formal logical structures. This has obviously been associated with an increasing neglection of a religious interpretation of the sky, i.e. the abandoning of initial astral myths. Advances in agriculture made the search and finding of various calendar symbols in the sky increasingly more important, whereas the development of science created the need to construct a description of the sky, a common stellar map, that would be uniformly and commonly understood by all scholars.

Therefore, it is possible that different layers of texts associated with different constellations consisting of the same stars and their names existed in the context of folk astronomy. While in some sense, Estonian folk astronomy is in a highly favourable situation as relevant material has been collected systematically, even if a little late, it is actually possible to differentiate some of these layers. The most problematic aspect here is the effect of the official astronomical systematisation of the sky (such as the standard constellation map) on folk astronomy: classic constellation figures may have penetrated the popular knowledge of the sky with changed names, but also the rendition of any interpreter of constellations may be too constrained by the previously acquired visualisation of the sky, which, however, needs to be exercised for determining the stars.

In the text below, I have used the term classic star map to refer to the modern astronomical star map featuring names that are mostly based on ancient mythology. 


\section{DIFFERENT CONSTELLATIONS}

In the context of this article, the term constellation must be defined as an independent subject formed of a grouping of stars, who or which is a participant in the corresponding motif under discussion. For example, Cancer would be a crab defined with the stars located in the areas of the current constellation of Cancer, who behaves exactly like a crab that bites Hercules, fighting the hydra, in the leg and is then squashed. The number of the stars in the same area of sky that form the subject may be different in different layers. One star can also be the subject, i.e. a constellation in the current context and several subjects may act within the borders of a single modern constellation.

Through the ages, people in different regions have harboured different views of stars as well as their formation, but the binding link here is the development from the celestial equivalents of single objects to more complex abstractions.

I have analysed the possible stages in the development of a constellation on the basis of accounts about the Orion constellation. Orion contains bright stars which are easily discerned in the sky and they form an easily recognisable grouping of reasonable size, which is why Orion is one of the best known non-astrological constellations in folk astronomy.

\subsection{Star as the Subject, Subject as the Constellation}

A star was probably the primary constellation. Stars that clearly stood out from amongst others were given names and explanations why particular names had been given to them, what they were doing there and maybe also a story about how they ended up in the sky. This means that the star was personified for the viewer, an independent subject that followed its own course of life and went about its own business. Many of its qualities later transferred onto groups formed of several stars or constellations. The star field of the Teleuts described by Uno Holmberg (1927, probably based on the works of Bogoras-Tan), is a fine example of such an image of the sky. 


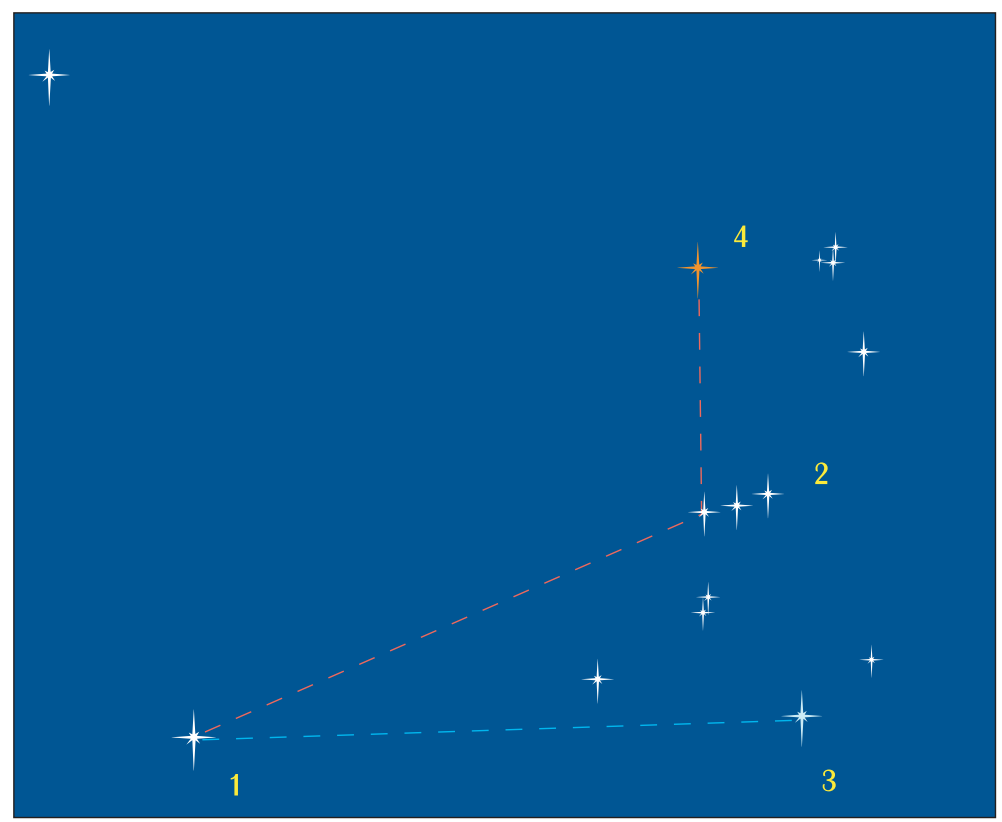

Figure 1. The Teleutian starfield: 1 - the hunter (Sirius), 2 -three deer, 3 - the arrow that missed (Rigel), 4-the arrow that hit target (Betelgeuse).

Illustration of the description is presented in Figure 1, which depicts the sky around the constellation of Orion. Sirius (1) is a hunter who is hunting three deer (2) and has shot two arrows. One of the arrows (Rigel, 3) missed its target and is of a bluish colour and the other (Betelgeuse, 4) has hit one of the deer and continues its flight, red with blood.

On the one hand, this is an example characterising pure astral mythology - the stars are precisely defined in the text and the connection between them has been described. This example represents direct projection of real life onto the sky: a specific hunting scene that may occur in any forest at any time. As said before, every star described here is a subject, they have specific features, a goal and an objective. The visual narrative itself consists of the activities of different subjects. 
The description of the Big Dipper recorded from the Yenisei Ostyaks (Khanty) is similar - three hunters hunting one or more elks. The first of the hunters is a Tungus, the second is an Ostyak, who carries a small kettle on his belt (Mizar and Alcor) and the third is a Russian (Holmberg 1927).

The motif of the cosmic hunt is rather widespread (see Berezkin 2005), and it has also been used in more complicated and periodic descriptions. I have taken a look at one of such options in my earlier article on the Milky Way (Kuperjanov 2002).

\subsubsection{Earthly Sky}

Different projections have also been possible: in these the stars in the sky are projected onto earthly objects and if there are no suitable objects, they will be created.

An example of one such case has been given by Egyptologist Robert Bauval, whose measuring has demonstrated a connection between the constellation of Orion and the placement of the pyramids along the River Nile. Bauval has explained it through religion: every living or departed pharaoh is assigned a star, and in the event of the pharaoh's death, a specific ritual will celebrate the old pharaoh's ascent to the sky and the sky giving "birth" to the new pharaoh (Bauval \& Gilbert 1995). Here the star is again a separate subject and the Milky Way represents the heavenly projection of the Nile.

\subsection{Entities consisting of small groups of stars?}

Such constellations are small groups of stars - originally, the stars of these groups have been differentiated on the basis of certain characteristics, as in the Big Dipper example above, but later they are interpreted as three goats, haymakers, kings, etc. An account suggesting that in German folk astronomy Orion's Belt symbolised the Three Holy Kings, can be found in the work by of Karl Otfried Müller that will be addressed below.

The three stars of the belt of Orion have probably been widely known in Europe without any closer specification and differentiation of stars. Narratives and explanations why they were interpreted as kings, goats, haymakers, or something similar have mostly been lost by now. A similar case is also the description of the Big Dipper as 
seven men or brothers, which was very widespread among Asian people (Holmberg 1927). Similar male figures can also be seen in the recently published Macedonian sky map (Cenev 2002).

\subsection{Small complete constellations}

The three stars in Orion' Belt form an entity, a spear, for example, while the stars themselves only have the role of forming the image, and their individual characteristics are not relevant as far as the constellation is concerned. This is a more abstract image and differs mainly and decisively from the previous clause in that even though the stars are the same, they no longer form the "Three Kings" but a single subject consisting of three stars (Figure $2, \mathrm{~A}$ ).

Such an interpretation of stars in the sky has been recorded on the Estonian islands (e.g. Uued ja Vanad Sauatähed or New and Old Staff Stars). Other information from the same area also implies that the known constellations were small, and their names were mostly associated with calendar days. This was first noted by Robert Livländer, who said that even the Big Dipper is known to the island people more as the landlord, ox and wolf, shaft and wheels (Livländer 1923).
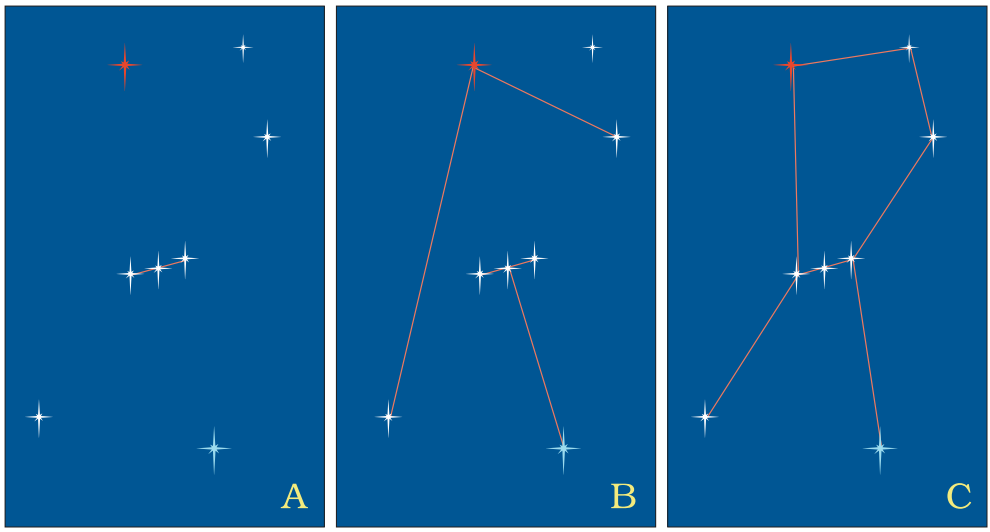

Figure 2. Different constellations. A-small compact constellation (e.g. Spear), B-the flail and rake, $\mathrm{C}$ - the Orion (only the brighter stars). 


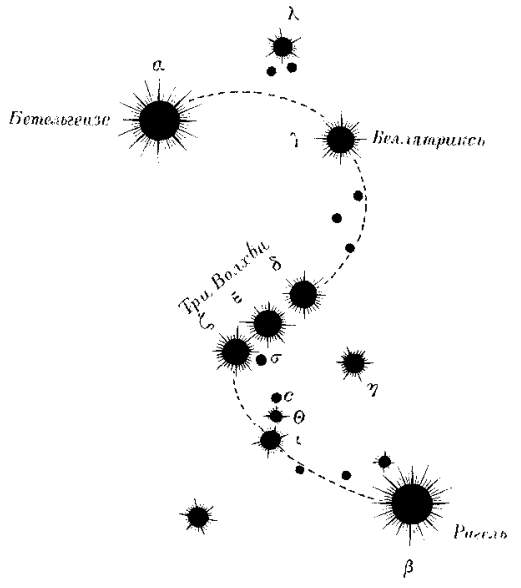

Figure 3. The Orion as a snake.

\subsection{Large non-traditional constellations}

While the constellations discussed above are small, consisting of just one to a couple of stars that are close to each other and covered a rather small angle of vision, large constellations tend to include brighter stars and cover an extensive area of the sky.

One possible and very unique image created by stars belonging in the Orion star field is the snake (In Estonian Siulik).

Such a large constellation can belong to a complicated system created by means of developed observation of the sky and strong generalisation. The constellation has acquired dimensions characteristic of the classic description of the starry sky, though differs considerably in nature.

This constellation is half hypothetical and the possibility of its existence is supported by some recorded accounts from Central Estonia. Relying on these materials, the association of Siulik and the 
constellation of Orion was thought possible already by Paul-Egon Prüller (Prüller 1968) and a book illustration published at the turn of the 19th and 20th century (Figure 3 ) shows a picture of the constellation of Orion, where bright stars are joined with a winding line (Klein 1900). It is possible that the names Odamus (acknowledged as a very old name of unclear etymology) and Ridamus originate in the same layer of marking the sky than Siulik, even though in the latter case it may also represent the Estonian version of the constellation of Andromeda in the classic sky.

\subsection{Widely known constellations that have probably been influenced by the classic celestial map}

The brighter stars in complex and larger constellations allow simpler figures to be created. Connecting Orion to tools used in threshing with a flail and a rake (Figure 2, B), is widespread in the Estonian tradition. Such representation of stars is known mainly in Southern Estonia; in Northern Estonia and the Setu region two flails were known, the same could apply to the western parts of Russia.

Such complicated representations are probably associated with the influence of official astronomy. The size of a constellation corresponds to the one presented on the traditional star map, but it has also been given a common explanation associated with agrarian activities and chronology, whereas many names arising from this, such as the Big Dipper, may be traced back to the ancient world either directly or by mediation of Germanic loans, where Euripides, for example, has simultaneously used both the names 'bear' and 'dipper' (Müller 1978). The same constellation has also been known as a cart or carriage elsewhere, also in China, which means that this must have been a truly universal name. There are also many hypotheses about the origin of the name 'bear' - according to a text referring to Hesiod, Arcadia can be considered to be one (Müller 1978). The nature of heavenly bears has been discussed in the past and this discussion is still ongoing, and many researchers consider them among the oldest of constellations (see e.g. Frank 1996).

\subsection{Constellations on the classic celestial map}

Standards of figures of constellations have not been established in modern astronomy and thus may vary to some extent on different 
star maps, ranging from simply joining the brightest stars to very detailed illustrations of stars drawn in the last century by H.A. Rey (Hans Augusto Reyersbach 1898-1977), author of several children's books, who tried to illustrate the mythological names of constellations (first published in 1952 in the book The Stars: A New Way to See Them).

The formation of constellations on the traditional star map is a mixture of loans originating in early civilised cultures (e.g. most of the Zodiac star signs definitely have this background) and areas of the sky mapped at different times. This is why their sizes differ. One of the largest ones, Argo Navis, was divided into parts in the course of later standardisation. Sail, Keel, Stern became separate constellations.

The borders of constellations have been strictly defined since 1928, the formed star field constitutes a constellation that includes all the stars that are projected onto this field. Therefore, the constellation of Orion is an outlined star field, in which many figures can be seen for the purpose of orientation and description, beginning from the simple connection of the seven brightest stars with straight lines (Figure 2, C) to the imitation of a hunter or warrior armed with a bow and sword.

\section{DEVELOPMENT OF THE CLASSIC CELESTIAL MAP}

Andromeda was a princess of Aethiopia, daughter of Cepheus and Cassiopeia. The vanity of her mother drew the vengeance of the Nereids, daughters of the sea god Nereus, so much that the daughter was also punished. A terrible sea monster, Whale (Cetus), was sent to ravage the coasts of Aethiopia, and it devoured the subjects of Cepheus. The Oracle had predicted that the Whale could only be pleased by the sacrifice of Andromeda and this left her father with no choice but to chain her daughter to a rock on the shore. She is still standing there and waiting for the Whale. The other characters of the myth are nearby-Cepheus and Cassiopeia, hero Perseus, who set Andromeda free and the ugly Whale can be seen far in the south. (Jaaniste \& Saar 1990: 82) 
This is one of many introductions of a constellation known all over the world. This introduction may seem to suggest that the sky map is a collection of old star myths and that ancient mythology and the sky have always been closely interrelated.

This is how the ancient sky map became to be perceived as mythological, - we have a number of beliefs based on this mythology, we pay money for predictions for future based on this mythology and their publication in newspapers increases the sales. But how mythological is the sky map and are there any other grounds to these beliefs except for public habit?

To answer this question, we have to take a look at how and for what reasons has the ancient sky map developed and how have the constellations been assigned these names. This has been studied by Karl Otfried Müller (1797-1840), whose Prolegomena zu einer wissenschaftlichen Mythologie or Introduction to a Scientific System of Mythology represents the first attempt to observe the formation of the traditional sky map (Appendix IX to the Chapter On Astronomical Mythi). He has taken a look at the names of constellations in the works of ancient authors according to chronology. His results could be presented as follows:

* The primary constellation, or, to be more precise, the star cluster that was assigned a myth-based name by Hesiod, was the Pleiades. Previously the constellation had been known under the name Ship Stars (calendar stars, their appearance marking the beginning of the navigation season) and here they have simply been renamed. The new name does not have a primary astral mythological content. The new name of 'the Rain Stars' - the Hyades - also originates from here. In terms of physics, the renaming has been prompted by precession. This is very likely the reason why these star clusters lost their calendar function.

* The constellation of the Boeotian war god Orion was observed in the sky before the Pleiades were renamed and may therefore be the only ancient constellation of astral mythological content. Since Orion moves behind the newly named Pleiades, ancient Greek poets came up with the phrase that Orion is chasing the Pleiades, which later developed into a narrative similar to a true astral myth based on the story of Oarion who is trying to catch the Pleiades. 
The combination dates back to Homer, who made Sirius the dog of Orion and changed the former war god into a hunter once and for all. Sirius was a star that was probably a cult object even before and dogs were allegedly sacrificed to it. Thus developed a longer story of a hunter who disgraced Merope. Over time, this story transformed into an original myth and also an astral myth, because by this narrative the actual relation between the stars in the sky is recorded and explained and a religious explanation for their existence is given.

* Other names of constellations originating in Greek mythology cannot be interpreted through astral mythology; they have emerged from the need to name and connect new areas that have been more precisely defined. Even though the names themselves stem from classical mythology, their relation to stars is rather unimportant.

* Many constellation names in the traditional sky have been borrowed - they emerged in the Greek sky system when the need to outline a certain part of the sky arose. The original mythological content of these constellations was not important. This includes most of the Zodiac constellations, which have been borrowed from the popular astronomy of other cultures.

In sum, Karl Otfried Müller claims that regardless of extensive research he could not find any later myths, even a most primitive fragment, that would define the form or location of a constellation in the sky. This means that the classic sky map is a long, nonhomogeneous story, in which a direct link between stars and mythology is generally missing. However, a narrative arises from star clusters that are assigned a logical explanation, and that helps to orientate in the sky and describes the location of the neighbouring stars through the so-called mythological connections. For example, the family of King Cepheus - a deeply mythological and family-centred description starting with the old King and ending with the head of Medusa, slain by his son-in-law. This fixes the arrangement of the stars in the sky. Next to Cepheus, the King of Aethiopia, Queen Cassiopeia is located, below them their daughter Andromeda and next to her heroic Perseus (see the example above). Actually, apart from the mythological names given to the images formed by stars, there is no other connection with actual stars. This means that our official sky map is pseudomythological since mythological 
content has been given to objects that have no essential relation to mythology and only a mnemonic function has been given to the corresponding mythological narrative. ${ }^{1}$

Vilmos Voigt has discussed the semiotic aspects associated with the development of the sky map (Voigt 2002).

\section{CHRISTIAN CONSTELLATIONS}

The traditional sky map can conditionally be considered pseudomythological. The mythological element it contains has a largely mnemonic meaning. However, there are several known attempts to create a sky map that are undisputedly artificial through and through. Such maps rely heavily on the traditional star map, previously known constellations are given new names and they are often also assigned a narrative that corresponds to a new content. The purpose of compiling maps is usually (1) to make the names of constellations correspond to religious beliefs, or (2) to translate/ create a sky map in a national language by replacing the characters originating in ancient mythology with local mythological creatures, or (3) just for the compiler's amusement.

Until now, no attempts to rename the stellar sky have attracted enough support for a wider spread. However, in terms of folk astronomy, the Christian description has been rather successful (I call it a description because not all variants directly contain a sky map).

The first Christian description of the sky worth mentioning originates in the 6th century and was provided by Saint Gregory of Tours. His De cursu stellarum written in 573, the objective of which was mainly to explain the chronology for monks, also described the Greater Cross (the Swan - Cygnus) and the Lesser Cross (the Dolphin - Delphinus) that are also widely known in current European folk astronomy.

The Christian approach to the sky has been continuously and constantly developed further. Twelve tribes are mentioned, supposedly traceable to the twelve apostles of the Old Testament; this is followed by an attempt to replace the names of Zodiac constellations with the names of these apostles. There are also attempts to project other things originating in the Scriptures into the sky. The high- 


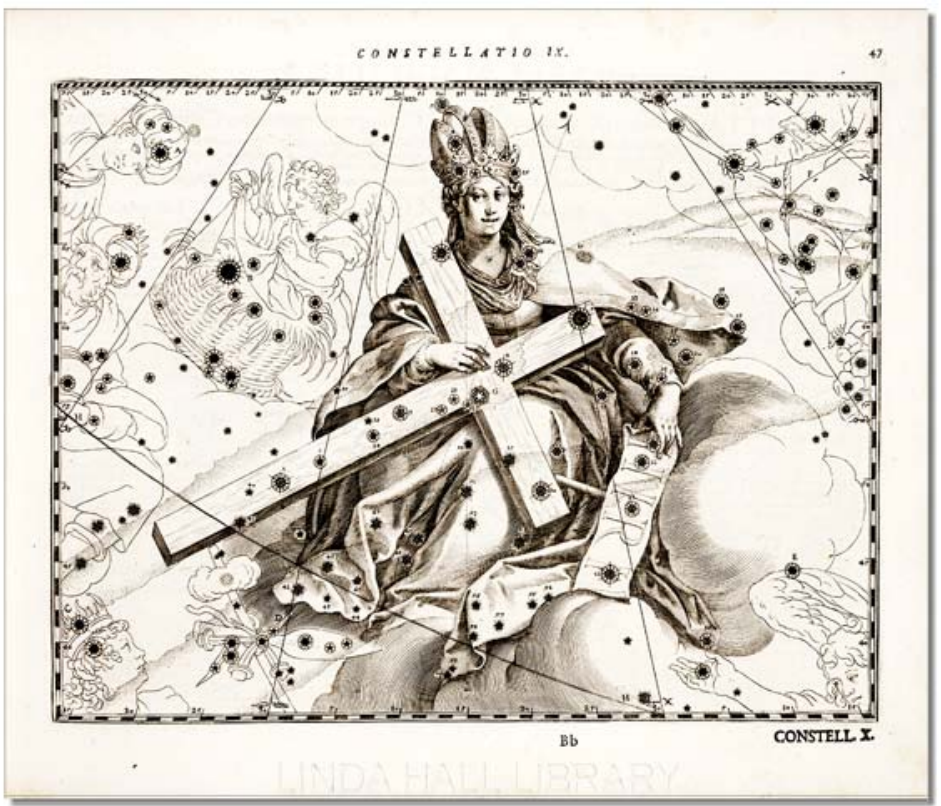

Figure 4. St. Helena's Cross from Schiller's atlas (Linda Hall Library).

light of such attempts arrived in 1627 when Jesuit Julius Schiller published his Coelum Stellarium Christianum (Schiller 1627) in Augsburg. It was an attempt to replace all the current names derived from ancient mythology on the official star map and replace these with Christian names. The Zodiac was again composed of the twelve apostles, the Swan is depicted as the Cross of St. Helena (known in some European folk astronomies) and Orion has become Joseph the Carpenter, the stepfather of Jesus (this connection is also spread).

The continuity of all such attempts was usually broken and similarly, Julius Schiller did not use many works of his predecessors. The constellation of Big Dipper (Ursa Major) is a fine example of Schiller's map's distance from reality - it is no longer St. Martin known from hagiographic texts, who performed miracles with his peasant's cart, and neither is it prophet Elijah ascending to heaven in his chariot of fire; now it is the boat of St. Peter. 
Even though Andreas Cellarius published Schiller's map in his star atlas Atlas coelestis seu armonia macrocosmica as late as in 1661, this attempt failed to take off regardless of being published in print several times and the relatively favourable ideological situation. Julius Schiller's map became an antique rarity. But regardless of this, similar attempts are still being undertaken by many religious movements and New Age followers, even though there is, of course, not too much common ground between their and Schiller's work.

One curious work from the same period is Colum Heraldicum the name generally used in various articles, Heraldica Caeli Facies Europaeorum, 1686, 1688 Biographisch-Bibliographisches Kirchenlexikon) by Erhard Weigel, published in Jena in 1688 and as a globe in 1699 (see Globe) - however, I have so far failed to come upon a comprehesive overview.

\section{ADO GRENZSTEIN'S CELESTIAL MAP FROM 1886}

There have been attempts to create a sky map in the Estonian language. In 1886, Ado Grenzstein published the first star map as an extra to the Olevik newspaper and printed using the wood engraving technique.

This map (Grenzstein 1886) can be considered a true pseudomythological sky map. The names of 55 objects in the sky have been included on the map following the National-Romantic spirit of the 19 th century. Some of these names have been in actual use (stars of the Big Dipper, Bow, Haystack, etc.), some partially overlapped popular names (Spear, Swedish Horse), or are translations of the traditional map (Herder). Most of it, however, is the creation of the author's fantasy, through which shines the attempt to try and create a fully Estonian-language sky map (without using direct translation of the names of traditional constellations) and a national sky pantheon that would be based on the literature containing artificial National-Romantic mythology. A detailed description of this star map has been previously published by Charles Villmann (Villmann 1968) and the list of names on the star map has also been presented in the book Eesti taevas (Estonian Sky - Kuperjanov 2003: 193). 
Unfortunately, this sky map did not become popular among the people either. At the beginning of the 20th century, however, the names of many folk-astronomical constellations defined by Jakob Hurt were printed on the sky maps published in books. Paul-Egon Prüller published several articles on the basis of the materials collected by Hurt and others and the first folk astronomical star map was created and finally published in 1968 . However, it has to be noted that the sky map instilled in the collective mind as the Estonian map is actually fiction, in which images belonging in different regions and at various stages of constellation evolution have been placed onto one sheet. But since this map has been distributed in this form for decades, by now it can be said that this is the perception Estonian people have of the sky, or a truly ethnoastronomical phenomenon.

Neither the Christian nor the map created by Ado Grenzstein were successful in replacing the traditional sky map. The reason why they failed is that the traditional sky map had already become a standard in the ancient times. Even though changes have been made to this map over time, some constellations have changed place, some have appeared and some disappeared, it has played a defining role in the culture of the Old World in terms of science and navigation. The local attempt by Ado Grenzstein and the somewhat more ambitious project of Julius Schiller left no trace on folk astronomy, but this has been achieved by earlier Christian interpretations of constellations from where the Greater Cross and the Lesser Cross and Elijah's chariot of fire have reached folk astronomy and become widespread.

\section{CREATE YOUR OWN SKY MAP}

The sky maps of Julius Schiller and Ado Grenzstein could also be included in this chapter; they are only set apart from other such maps in their style, ambition and the fact that they were published in print as real star maps.

Many have tried to define the patterns of stars for themselves when looking at the sky. Some have recorded their visions and shared them with others, like in the following example. 
On this map new constellations have been drawn on the map template created by planetarium program and the names represented are Hippie and the Evil President and, as befits a desert-like area, also Devilus Dustia and the Water Truck. The Milky Way has become the Dusty Way. Such, often humorous maps, are usually based on the ordinary star map, on which the figures of constellations are changed a little and are given new names. The legend associated with the map may be topical or follow a script known to some group.

Brad Templeton, the author of the map given as an example here, has commented the map describing how they selected the Vault of

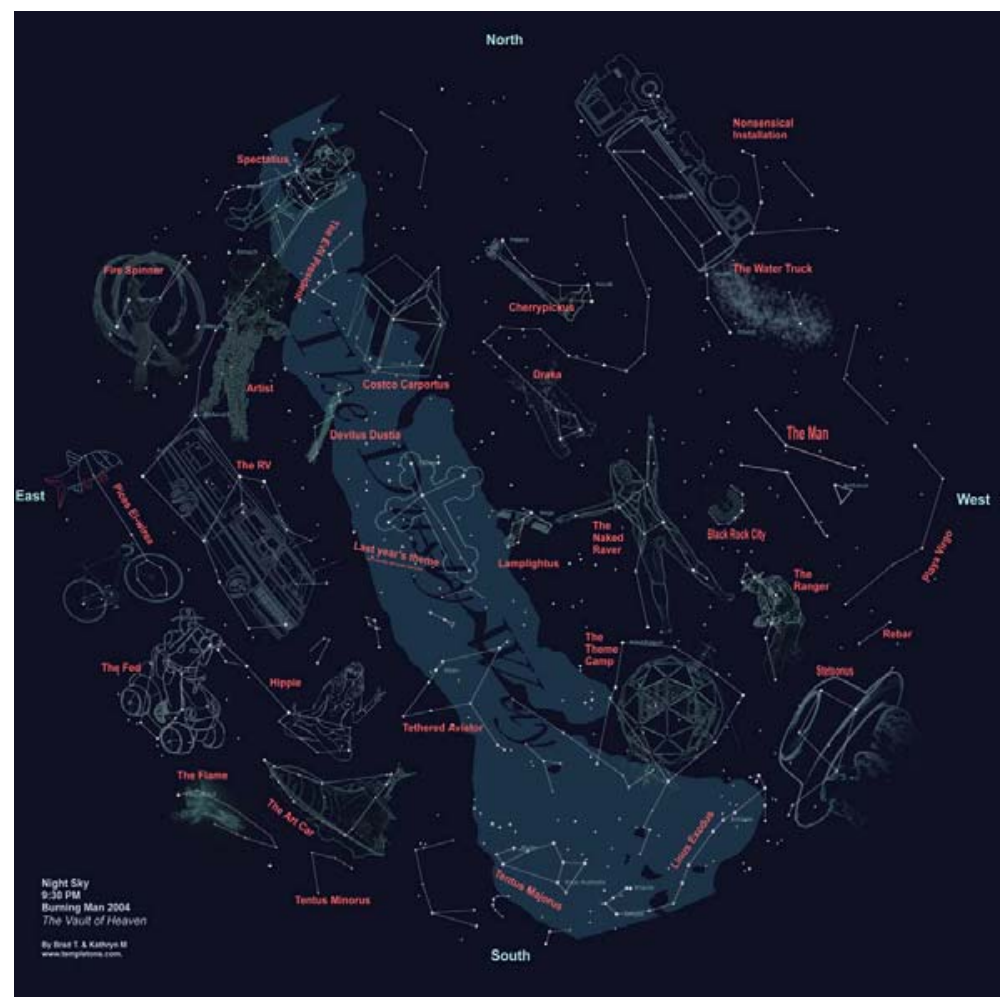

Figure 5. Brad Templeton's map of Vault of Heaven.

http://www.templetons.com/images/vault.jpg 
Heaven as the theme for the 2004 Burning Man happening (a temporary town is established in the Nevada Desert for a month, which will be visited by about 30,000 people and where performances are held) and then created a new sky map on the template created by the planetarium program Kstars (Templeton 2004). Sky maps have also been prepared for several role plays, but they are often based on artificial, unearthly templates (see for example Play.net).

The representation of the sky of the Ests (Chudes) described by Aleksander Heintalu (Sass of Vigala, a well-known folk healer) is a somewhat more complicated case as it has used a tumble of names from the Estonian sky map by Paul-Egon Prüller (using a selection of constellation names recorded in different regions) and constellations of offical astronomy, some of which are presented with their own names and some have been renamed (Heintalu 2001). I have no doubt that this solution also finds followers in certain groups, but in the context of folk astronomy this is nothing more than another expression of contemporary folklore and artificial mythology.

\subsection{Elvish sky lore}

Many writers have created pseudomythological worlds that have often been written in the cosmogonic and mythological key. A good example is John Ronald Reuel Tolkien, whose work is best known for its complexity and variety of mythological aspects. Elvish Star Lore (Manning 2003), an article written by Jim Manning who works in the Taylor Planetarium in Montana, US, analyses the connections to cosmology and the sky in the works of J. R. R. Tolkien and claims that Tolkien has been very consistent in the creation of his pseudomythology, using methods of comparative mythology as well as astronomy. In his texts, the Moon moves and the phases of the Moon occur in exact chronological sequence. The author of the article claims that everything is very faithful in astronomical aspects, but the occurrence of precession has not been taken into consideration, i.e. the expanse of the sky corresponds to the one that could be observed in the 20th century but not to what is was thousands of years ago. Using the pseudomythological texts created by Tolkien (particularly the elvish lore in them) and trying to set the names and descriptions given there in concordance with the sky map, Jim Manning presents a picture that resembles the typical ethnoastro- 
nomical findings arrived at on the basis of archive texts collected throughout times. There is a red star and a blue star, there are several names of celestial objects that cannot be identified, but the ones that can be identified within certain confidence limits are Orion, Sirius, the Big Dipper, Cassiopeia and of course the Pleiades. The planet that has been highlighted is Venus. Therefore, even though in the given case we know the bases of the astronomical aspects of myth creation (classic astronomy is one of the most important aspects in this context), it is still very difficult to identify other, less clearly delineated constellations on the basis of these texts.

\subsection{The issue of authenticity}

Is it possible to tell an authentic folk astronomic sky map apart from an artificial creation on the basis of certain features? No, not really. I will attempt to rationalise it as follows:

1. Since constellations of the current classic sky became the established standard already in ancient times (navigation on sea was based on that and the highly developed astronomy of the Arab world mainly used ancient constellations), the fact that a folk constellation consists of the same stars that belong into the corresponding official constellation cannot be set as a criterion for ruling out folk astronomy in the Old World. It is possible that a constellation in folk astronomy is a classical constellation that has simply been renamed according to a given culture and an astral mythological content created for it.

2. Since constellations in the classic stellar sky are generally of average size and rather logically outlined, then it is also possible that some nations have come up with similar patterns when observing the sky.

3. Artificial creation also tends to be limited to redrawing classical constellations, because people are used to thinking along the lines of the standard sky map.

4. Interpretation of texts containing possible folk astronomic information is mainly based on the known map. Therefore, it is not always possible to define a constellation fixed in folk astronomy as, 
for example, an old constellation characteristic only of Estonia, because descriptions of the sky known from the ancient times may have been used (either intentionally or unintentionally) during the initial formation stage of the constellation or in its later description.

\section{ATTEMPT TO RECONSTRUCT FOLK ASTRONOMY}

\subsection{Star myths of the Vikings - new conceptualisation of Nordic mythology}

As far as is known, material recorded about the wisdom of stars among the Scandinavians is relatively scanty. Bjorn Jónsson (19201995), a resident of Canada, aspired to find links between the Old Scandinavian and traditional stellar skies. For this purpose, he selected extracts of possible astronomical content from the works of Snorri Sturluson and used these to build a cosmological system. He published the results in his book Star Myths of the Vikings (Jónsson 1994).

At first, the author claims that Snorri's Edda (also known as the Younger Edda or the Prose Edda), which dates back to the 13th century, can to some extent be interpreted as a collection of astronomical texts, even though its author, Snorri Sturluson, has not pointed that out, possibly owing to the reason that church officials of the time viewed any knowledge of astronomy as an expression of a pagan mindset. The author also claims that since in the prologue to Snorri's Edda, Sturluson has referred to the similarity of the Scandinavian polytheist system to that of the antiquities, he has chosen to use the mythological schemes of the Old World in his interpretations. Considering the knowledge Vikings had in those times, this methodology is perfectly acceptable. It is known that Oddi Helgason, who was called Stjerna Oddi (Star Oddi), developed tables on the basis of his observations (approx. 1100-1150), which enabled to perform calendar calculations, and determine the time of solstices and equinoxes, the divergence from the Julian calendar, weekly height of the sun and the azimuths of sunrise and sunset. Therefore as late as in the 12 th century, knowledge of astronomy in 
Iceland met the general standards of the time and probably corresponded to the knowledge in all of Europe.

Secondly, since in the 12 th century astronomy was practiced at a high level and was very popular, a scientific description of the world, including a sky map, must have been in use at the time.

Thirdly, Vikings had long been known as skilled navigators. Their shipways reached deep into ancient areas and navigation was based on good knowledge of the stellar sky. It is likely that astronomy proper reached the Viking world considerably earlier than in the specified 12 th century.

Therefore, it is very likely that a traditional sky map could have been used in these regions in the 13th century (and, of course, much earlier), on the basis of which constellations had been named/interpreted according to a given mythology and then supported with a corresponding narrative to simplify orientation. A similar transformation of 'foreign' knowledge into 'own' has been noted in many other areas of folk knowledge.

Bjorn Jónsson has started with interpreting constellations in the Milky Way area, which owing to its peculiarity can be used as a key. The Milky Way represents, of course, the world tree Yggdrasill.

It is very difficult to ascribe the interpretation of this area of sky to any particular nation. The concept of the world tree and the birds that live on its branches and the snake on its roots are highly universal motifs. It has been thought that visually the Milky Way is more similar to a tree especially in Northern areas - Heino Eelsalu suggests that the concept of an association between the world tree and the Milky Way could have emerged about six thousand years ago at latitudes 30-40 degrees North (Eelsalu 1985: 69) - at lower latitudes, the association with a pathway or a river is more common, whereas the latter is almost never mentioned in the north.

Therefore identifying the large ash tree Yggdrasill with the Milky Way is a logical solution for Scandinavian regions. The Milky Way is observed far into the south. This is highly likely considering that the Vikings also travelled in the Mediterranean area. The interpretation of some constellations on the Milky Way (Swan, Eagle, 


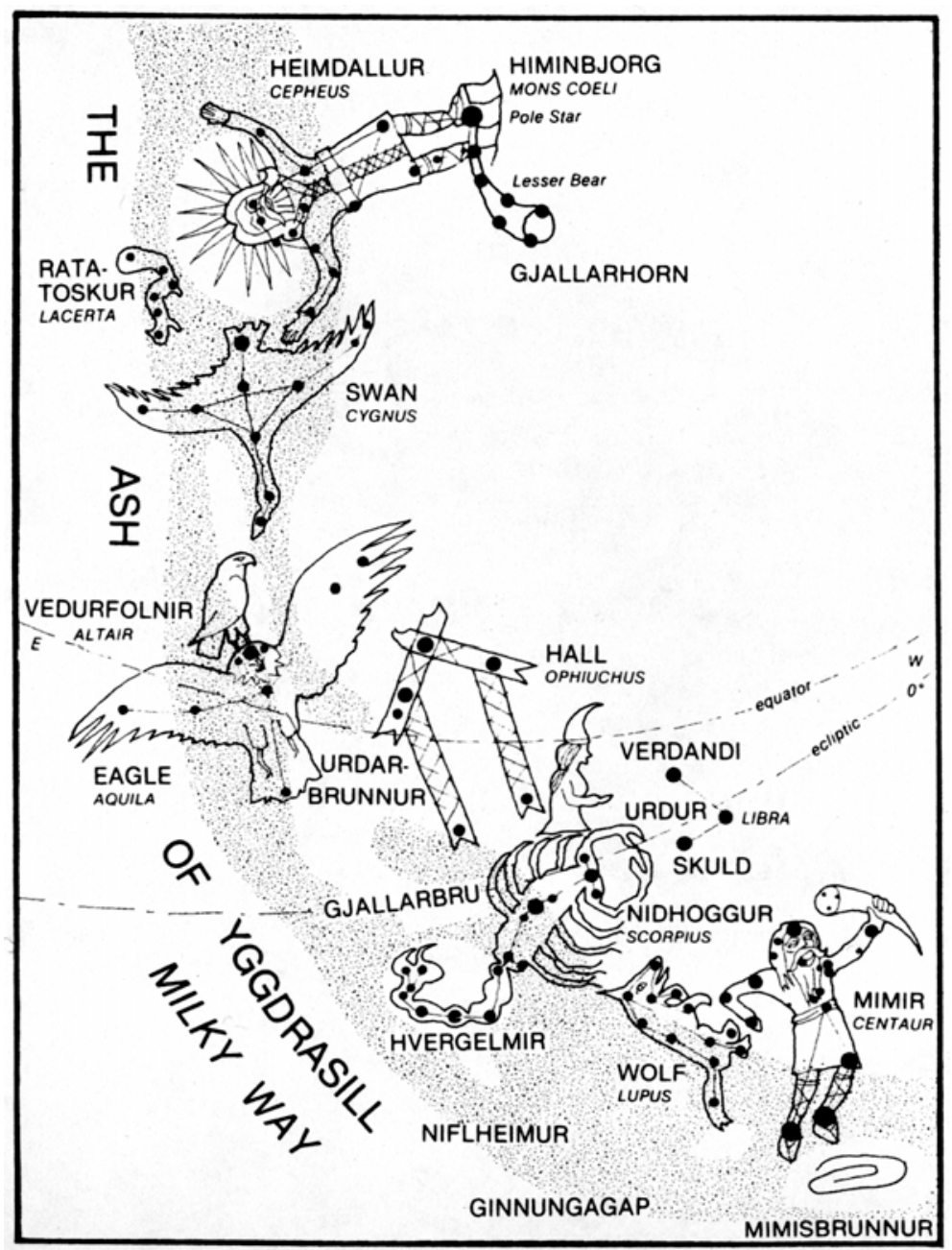

Figure 6. The world tree Yggdrasill according to Bjorn Jónsson.

Ratatosk [constellation of Squirrel (Lizard)], Snake) is also likely, and the rest may already be too hypothetical.

The ecliptic is important in the cosmological sense; the abode of the gods is above the ecliptic and the underworld inhabited by monsters and the dead is below. Applying this principle and proceeding 
from the world tree (the giant ash tree Yggdrasill), Bjorn Jónsson has started to associate the text of $E d d a$ with the sky map. The result of the interpretation is of course arguable, but in principle, such an approach is justified. The result is a unique version of the traditional sky map, which even in those days was probably largely an artificial creation. If such a representation of the sky (sky map) did exist and was widely used, then this could have wiped out earlier truly folk astronomical knowledge of the sky. But because it is relatively new and nonauthentic (folk) astronomy, then it was not preserved and was entirely replaced by the classical sky map in the course of later ideological attacks. And this also yields the hypothetical explanation why so little folk astronomical material has been preserved in Scandinavia.

\section{CONCLUSION}

1. The traditional sky map covered with mythological names is by no means mythological; on the star map the name is more important than the myth associated with it. For example, there are constellations in the southern sky the names of which lack any trace of mythology - a constellation may easily be called Clock, Microscope or Compass. At the same time, older groups of names constitute individual narratives that help to remind of the way constellations are positioned in relation to each other. Originally, these narratives are either artificial creations, loans from earlier civilisations or the origin has remained relatively unknown, but have a possible earlier astral mythological content, such as the area on the traditional sky map that borders the Milky Way and the Cygnus-Sagittarius constellations, which has definitely been very attention-worthy owing to the more intense brightness of the areas where the Milky Way splits and that are close to the galactic nucleus. But the descriptions provided by ancient mythology seem too forced in this area. It would be far more logical to find a projection of the world tree with birds and a snake in the sky than, for example, a story about Zeus, who visited Leda, the Queen of Sparta, in the form of a swan or the constellation of Eagle (Aquila), for which there are no common explanations as to why it can be seen in the sky or what it is doing there. 
2. The traditional sky map is a definite and recognised sign system, which has been the standard (to a certain extent, because several changes have been made to it). This is why discretionary renaming of constellations (even in favourable ideological conditions) has not been successful. Whereas the classic sky map (with the early Catholic practices in astrognosy) has shaped folk astronomy of the first millennium, at least in Europe.

3. Artificially created pseudomythological sky maps are often just attempts to rename the established sky map. The names used have often not been developed in sufficient detail or are fixed in collective mind, which is why the likelihood of their spread and usage is even smaller. At the same time we cannot disregard the possibility that this is the kind of mechanism which was used during some historical period to make the classic celestial map more popular the new names of constellations then also have roots in their own culture. In Estonia, such a representation of the sky may entail the constellations in materials recorded from Palmse - Ridamus (Andromeda), Nelikand 'Square' (Pegasus), Snake of North (Dragon Draco), etc. At the same time, it is also possible that in this case the classic map has not been directly adopted, but represents an instance of interference between an older layer of popular astronomy and the traditional sky map.

4. We cannot claim that the attempt of Bjorn Jónsson to restore the forgotten knowledge of the sky of the Vikings has resulted in an authentic mythological view of the sky. However, considering the global relations at the time and the predominance of oral culture, which possibly triggers the process mentioned in the previous paragraph, the existence of such Northern map is highly possible. Since hardly anything of this representation of the sky has been preserved in the original tradition, it is highly probable that this map as well as the knowledge of the sky the Vikings had at the time were no longer based on original astral myths and therefore did not represent so-called original folk astronomy. At the same time, the hidden assumption of the interpretation is the similarity between the classic sky map and the Viking sky map.

The key link here is the name. Whether there is any mythology behind the name or not is actually not that important, because real astral mythology is an unexpectedly rare phenomenon. However, 
inclusion of mythological motifs enables to construct a narrative or a mental sky map that is relatively easy to remember and helps to orientate in the stellar sky, especially in oral tradition.

I would like to conclude with a general note on folk astronomy and star myths. It seems that real star myths can only be found in layers in which every star constitues a separate subject. In terms of larger and more abstract constellations, original myths are replaced with artificial creation or loans. The development ends with the established traditional sky map.

\section{Comments}

${ }^{1}$ Unfortunately, even though Müller knows a lot about folk astronomy of those days, especially in terms of Orion that is known to our country people as the Three Holy Kings, neither he nor anyone else has recorded these observations in written form. It is evidently characteristic that people deal with a circle of topics that is scientifically popular, granting merits for a limited group of laymen and allowing to refer to other learned men and thereby securing one's academic career. The result is the thousands of works that briefly touch upon the mythological aspects of classical astronomy, while only a fraction of them are of any actual significance. But there are no proper written materials about the folk astronomy about these three kings.

\section{Acknowldegements}

The article is related to Estonian Science Foundation grant no 5117.

\section{References}

Bauval, Robert \& Gilbert, Adrian 1995. The Orion Mystery: Unlocking the Secrets of the Pyramids: A Revolutionary New Interpretation of the Ancient Enigma. Three Rivers Press.

Berezkin, Yuri 2005. Cosmic Hunt: Variants of Siberian-North American Myth. Folklore, 31. Tartu, pp. 79-100. http://www.folklore.ee/ folklore/vol31/berezkin.pdf

Cenev, Gjore 2002. Zvezdena Karta na Makedonskiot Narod - Sky Map of Macedonian People. Ethnoastronomy. Skopje. http:// www.mkc.org.mk/ethno.html 
Eelsalu, Heino 1985. Ajastult ajastule: [muinasastronoomia ja -kalendriloo uudsest käsitlusest] [From Era to Era. On Novel Treatments of Ancient Astronomy and Ancient Calendars]. Tallinn: Valgus.

Frank, Roslin 1996. Hunting the European Sky Bears: When Bears Ruled the Earth and Guarded the Gate of Heaven. Astronomical Traditions in Past Cultures. Proceedings of the First Annual General Meeting of the European Society for Astronomy in Culture (SEAC), Smolyan, Bulgaria, 31 August - 2 September 1993. Sofia: Institute of Astronomy, Bulgarian Academy of Sciences \& National Astronomical Observatory Rozhen, pp. 116-142.

Globe $=$ Celestial instruction globe. National Maritime Museum. http:// www.nmm.ac.uk/collections/explore/object.cfm?ID=GLB0086

Grenzstein, Ado 1886. Taeva-kaart [Sky Map]. Oleviku II hinnata erilisa [Second Special Free Addition to Olevik]. Tartu.

Heintalu, Aleksander 2001. Estide (tšuudide) hingestatud Ilm: Teadaandmise Raamat [The Animated World of Ests (Chudes): A Book of Announcement]. Männisalu: A. Heintalu.

Holmberg (= Harva), Uno 1927. The Mythology of All Races: In Thirteen Volumes IV: Finnougric, Siberian. Boston: Marshall Jones Company.

Jaaniste, Jaak \& Saar, Enn 1990. Täheatlas: Käsiraamat [Star Atlas: Handbook]. Tallinn: Valgus.

Jónsson, Bjorn 1994. Star Myths of the Vikings: A New Concept of Norse Mythology. Swan River: B. Jónsson.

Klein, German Iozef 1900. Astronomichestkie vechera: Ocherki iz istorii astronomii. Obschchedostupnaia Nauchnaia Biblioteka. St. Peteburg: Tovarischchestvo "Znanie".

Kuperjanov, Andres 2002. Names in Estonian Folk Astronomy - from 'Bird's Way' to 'Milky Way'. Folklore, 22. Tartu, pp. 49-61. http:// www.folklore.ee/folklore/vol22/milkyway.pdf

Kuperjanov, Andres 2003. Eesti taevas. Uskumusi ja tõlgendusi [Estonian Sky. Beliefs and Interpretations]. Tartu: EFI.

Livländer, Robert 1923. Vanade saarlaste täheteadus praegusel ajal. Mõned märkused ja lisandused Dr. J. Hurti "Eesti astronoomiale" [The Astronomy of Old Saaremaa People in Contemporary Times. Some Comments and Additions to Dr. J. Hurt's "Estonian Astronomy"]. Loodus, 8, pp. 484-494.

Manning, Jim 2003. Elvish Star Lore. Planetarian, 32 (4), pp. 14-22. http://www.ips-planetarium.org/planetarian/articles/elvish/elvish.pdf

Müller, Karl Otfried 1978. Introduction to a Scientific System of Mythology. New York: Arno Press. Reprint of the edition by Longman, Brown, Green and Longmans in London in 1844.

Play.net $=$ Constellations of the Northern Sky. Play.net: Multiplayer Online Games! http://www.play.net/gs4/info/tomes/constellations.asp 
Prüller, Paul-Egon 1968. Eesti rahvaastronoomia [Estonian Folk Astronomy]. Teaduse ajaloo lehekülgi Eestist, 1. Kogumik. Tallinn: Teaduste Akadeemia Kirjastus, pp. 9-70.

Rey, H. A. (= Reyersbach, Hans Augusto) 1952. The Stars, A New Way To See Them. Boston: Houghton Mifflin.

Schiller, Julius 1627. Coelum Stellarium Christianum. Linda Hall Library http://www.lindahall.org/services/digital/ebooks/schiller

Templeton, Brad 2004. Vault of Heaven Star Map. http:// www.templetons.com/brad/burn/starmap.htm

Villmann, Charles 1968. Esimene eestikeelne taevakaart [The First Sky Map in Estonian]. Teaduse ajaloo lehekülgi Eestist, 1. Kogumik. Tallinn: Teaduste Akadeemia Kirjastus, pp. 129-137.

Voigt, Vilmos 2002. Cosmographical maps (on Stars). Myth and Mentality. Studies in Folklore and Popular Thought. Siikala, Anna-Leena (ed.). Studia Fennica folkloristica = Suomalaisen Kirjallisuuden Seura 8. Helsinki: Finnish Literature Society, pp. 42-49. 